\title{
La propiedad personal sobre bienes muebles y el plan vinculado a la revolución energética. Retos y desafíos para el Derecho en Cuba
}

Marien Piorno Garcell* Loraine Céspedes Medina** http://dx.doi.org/10.21503/lex.v10i9.336

* Profesora Principal de Derecho sobre Bienes Universidad de Guantánamo marien@fd.cug.co.cu

** Profesora Principal de Derecho Administrativo Universidad de Guantánamo loraine@fd.cug.co.cu 


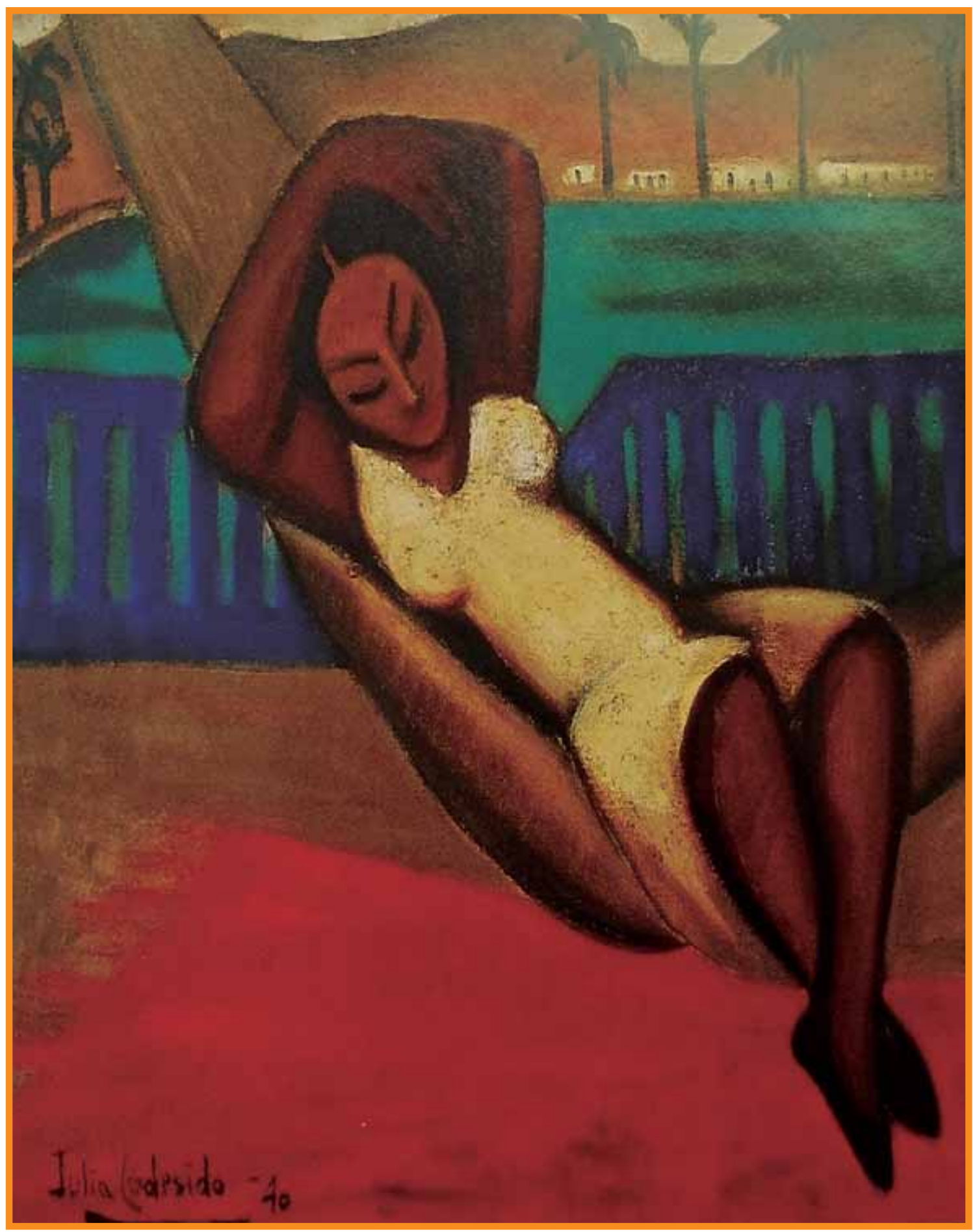

Huacachina. Colección Gruenberg. 


\title{
Resumen
}

El artículo parte de considerar que todo ordenamiento jurídico debe garantizar la seguridad que demandan las relaciones jurídicas que regula en su normativa. De ahí que sea necesario dotar al titular del derecho de propiedad personal de una adecuada formulación de las normas jurídicas, para que dentro de las limitaciones establecidas por la ley, reconozca las facultades y acciones que ostenta el sujeto sobre el bien que integra su patrimonio y proporcione tutela jurídica frente a la vulneración de su derecho, garantías que exigen la sumisión de los poderes públicos y de todos los ciudadanos y que tributa al cumplimiento de los principios de validez y eficacia del Derecho. Explica cómo la aplicación en el país del Plan vinculado a la Revolución Energética refleja, por un lado, un beneficio económico para la población cubana y, por otro lado, una relativa separación entre el Derecho y los poderes públicos, que afecta valores como la justicia y la seguridad jurídica, con gran incidencia en la propiedad personal sobre determinados bienes muebles, situación que ha motivado precisamente el desarrollo de este material científico.

\section{Palabras claves}

Derecho de propiedad, propiedad personal, bienes muebles, título de propiedad, políticas públicas.

\begin{abstract}
The article starts by considering the every legal ordinance must guarantee the protection demanded by the legal relations which are regulated in its own policy. Hence, it is necessary to provide the holder with the right to private property by offering an adequate formulation of the legal guidelines, making sure that the established legal boundaries recognize the power and actions the individual has upon his or her patrimony, conceding legal tutelage when facing infringement of right; these guarantees demand the submission of public and citizen authority leading to the effective implementation of Right. The article also explains how our nation's energy saving plan; on the one hand, provides benefits to our society, and on
\end{abstract}


the other hand, causes a relative separation between right and the civil power; creating the conditions for a crisis of societal values such as justice and legal security. This situation has a huge influence upon certain moveable chattel; consequently, it has been a motivational source to develop our investigation.

\section{Key Words}

Property right, private property, moveable chattel, public policies, title of property.

\section{Sumario:}

I. A modo de introducción. II. Apuntes sobre la propiedad personal en Cuba. III Incidencia del Plan vinculado a la Revolución Energética en la propiedad personal de bienes muebles de los ciudadanos cubanos. IV. Conclusiones. V. Referencias bibliográficas.

\section{A modo de introducción}

La Propiedad Personal es uno de los temas de mayor connotación social y jurídica en la panorámica cubana actual. Son considerables las investigaciones científicas desarrolladas en el país desde las perspectivas del Derecho sobre Bienes, con gran incidencia en el análisis exegético de la propiedad personal sobre la vivienda y menos frecuencia con respecto al estudio de la propiedad personal sobre bienes muebles.

No solo debemos centrar nuestra atención en materia inmobiliaria, sino también sobre la propiedad personal de bienes muebles, es decir, la propiedad personal sobre aquellos bienes sometidos al Plan vinculado al ahorro energético, objeto de preocupación tanto de la población cubana como de los juristas, pues la entrega o sustitución de artículos sin la emisión de documentos acreditativos de derechos reales sobre los mismos, ha generado que la mayoría de los ciudadanos acudan a los Bufetes Colectivos en busca de representación letrada, ante la imposibilidad de recuperar su bien de manos de quien lo detenta sin causa legítima; para instar al Tribunal competente contra el miembro de su núcleo familiar que al momento del cambio del artículo era la única persona con capacidad para asumir el compromiso de pago y ahora pretende acreditarse la titularidad del bien; para dividir el caudal hereditario sobre bienes que en un inicio pertenecían al causante y luego del cambio no tienen definido un titular; o para liquidar la comunidad matrimonial de bienes.

Ante la necesidad de documentos acreditativos de derechos reales sobre los efectos electrodomésticos y otros artículos que han sido objeto de la aplicación de este Plan, nuestro trabajo tiene el propósito de identificar y solucionar las consecuencias jurídicas que son 
materia de política pública, de modo que el Derecho garantice la seguridad jurídica que demandan las relaciones jurídicas que regula en su normativa. Para responder al objetivo propuesto, partimos de breves reflexiones teóricos-doctrinales, normativas y prácticas de las categorías sobre Propiedad Personal, Derecho de Propiedad Personal, así como del análisis del Plan vinculado al ahorro energético del país y su incidencia en el derecho positivo, expresamente determinados entre bienes muebles que integran la propiedad personal de nuestros ciudadanos cubanos.

\section{Apuntes sobre la propiedad personal en Cuba}

El Derecho de Propiedad denominado en la doctrina ius plenum in re corporali, ha sido un tema tratado desde la antigüedad. Para los romanos representaba el conjunto de todos los derechos que podía tener un individuo sobre aquellos bienes susceptibles de apropiación. En otras palabras, la posibilidad que tenía el titular de satisfacer su interés sobre determinado bien, limitado exclusivamente por las normas. ${ }^{1}$

Las nociones sobre el Derecho de Propiedad que fueron desarrolladas por los romanos sentaron las bases del derecho actual, aunque no fueron suficientes para ofrecer una definición acabada del término de propiedad que recogiera en su contenido todas las formas de propiedad reconocidas en Roma. No fue hasta la época de Justiniano que finalmente quedaron inmersas en una fórmula abstracta, general, que veía la propiedad como una relación única del hombre con las cosas.

Durante la Edad Media se rediseñaron varios enfoques socioeconómicos sobre la propiedad y a mediados del siglo XIX las injusticias del régimen capitalista desataron una fuerte lucha encaminada a poner fin a la propiedad privada. Marx y Engels, en este sentido, sostuvieron que lejos de abolir la apropiación personal de los productos del trabajo individual, indispensables para la vida humana, resultaba necesario eliminar la propiedad privada por tener como fundamento la explotación del trabajo ajeno. ${ }^{2}$

Con el surgimiento del sistema socialista se vio amenazado el régimen capitalista que hasta el momento gozaba de aceptación internacional. Los países europeos que implantaron

\footnotetext{
Los romanos concentraron el contenido del Derecho de Propiedad en tres grandes Derechos fundamentales: ius utendi, ius fruendi y ius abutendi. Para más detalles Vid. Fernández Bulté, Julio; Carreras Cuevas, Delio; Yánez, Rosa María, Manual de Derecho Romano, La Habana, Editorial Pueblo y Educación, 1982, págs. 104 y ss.

2 Ciertamente, la propiedad privada, base del orden económico burgués, condiciona las desigualdades sociales al ser la expresión más latente del dominio de un sector de la sociedad sobre otro. Refleja la subordinación de la clase oprimida — carente de los recursos económicos imprescindibles para satisfacer sus necesidades individuales — a los intereses de la clase que ostenta el poder económico, beneficiada con el excedente del trabajo de sus subordinados. Cfr. Rapa Álvarez, Vicente, "Propiedad Personal y otras formas de propiedad no previstas en la Constitución", en Revista Jurídica, La Habana, núm.3, 2009, págs. 125-126.
} 
el sistema socialista eliminaron la propiedad privada sobre los medios de producción. "Las constituciones derivadas de la revolución burguesa establecieron el derecho de propiedad como uno de los centros del orden social y político, como derecho de demarcación entre los poderes del Estado y el interés público y los poderes del particular y el interés privado. En el siglo Xx prevaleció la tendencia de destacar la dimensión social del derecho de propiedad". ${ }^{3}$

Esta situación cobró connotación en el plano nacional desde de 1959. El triunfo de la Revolución Cubana inició un proceso de cambio del régimen capitalista y de la propiedad privada — sustento de la base económica - por el régimen socialista, respaldado en la propiedad estatal socialista sobre los medios fundamentales de producción, que alcanzó su máxima expresión en la Constitución de 1976.

La Constitución reconoció en un inicio 5 formas de propiedad, luego con la reforma de 1992 incorporó nuevas formas de propiedad, pero ha sido invariable el carácter supremo dado a la propiedad estatal socialista sobre los medios fundamentales de producción. Esta propiedad integrada por los bienes colectivos que conforman el patrimonio del Estado, condiciona la existencia de la propiedad personal, toda vez que proporciona los medios fundamentales para garantizar la satisfacción de las necesidades e intereses esenciales de la población cubana.

La propiedad personal se encuentra regulada en el Artículo 21 de nuestra Constitución y en el Código Civil cubano de 1987, artículos del 156 al 158 de su Libro Segundo titulado "Derecho de Propiedad y otros Derechos sobre Bienes". Es entendida como el acto de apropiación de bienes de uso y consumo por los ciudadanos cubanos para la satisfacción de sus necesidades espirituales y materiales. Está integrada por bienes esencialmente corporales, muebles e inmuebles, que pueden distinguirse en tres grandes grupos:

1- Los bienes que son fruto del trabajo propio como los ingresos personales, cuentas de ahorro, jubilaciones, pensiones, estipendios.

2- Los bienes utilizados para el desarrollo del trabajo personal como los medios de transporte.

3- Bienes de uso doméstico, de primera necesidad, la vivienda y demás objetos destinados a satisfacer el interés personal de su titular.

La propiedad personal por sí sola no es suficiente para que el sujeto alcance el beneficio pretendido sobre el bien que la integra. Es preciso que éste pueda accionar directamente sobre ese bien y extraer la mayor utilidad económica del objeto con exclusión o prioridad

3 Tomado de Rivero Valdés, Orlando, Temas de Derechos Reales, Editorial Félix Varela, La Habana, 2001, págs.16-17. 
frente a terceros, lo que se materializa a través del ius utendi, el ius fruendi, el ius abutendi o ius disponendi y el ius vindicandi como facultades y acciones del derecho de propiedad personal.

Surge así la necesidad de dotar al titular del derecho de propiedad personal de seguridad jurídica, esto es, de una adecuada formulación de las normas del ordenamiento jurídico que dentro de los límites y limitaciones que se establezcan, reconozca las facultades y acciones que el individuo ostenta sobre el bien, así como dotarlo de tutela jurídica frente a la vulneración de su derecho, garantías que exigen la sumisión de los poderes públicos y de todos los ciudadanos y que tributa al cumplimiento de los principios de validez y eficacia del Derecho. No obstante, la panorámica cubana actual refleja una relativa separación entre el Derecho y determinadas políticas públicas del país que afecta valores como la justicia y la seguridad jurídica, cuestiones que abordaremos a continuación.

\section{Incidencia del Plan vinculado a la Revolución Energética en la propiedad personal de bienes muebles de los ciudadanos cubanos}

Nuestro mundo se caracteriza por la ampliación de las tareas de los poderes públicos. Son incontables las intervenciones normativas del Estado a través de medidas o providencias administrativas. En el marco nacional cubano es una realidad el establecimiento de políticas públicas para beneficio de la población y de la economía nacional, pero, en ocasiones, la no adopción de medidas previas al actuar de los órganos estatales ha lesionado el Derecho, por un lado, al privarlo de su finalidad de garantizarle a los individuos la seguridad jurídica que demandan determinadas situaciones; y, por otro lado, al dificultar a los operadores del Derecho del correcto discernimiento, interpretación y aplicación que corresponde en cada caso.

Muestra de ello lo constituye el desarrollo en el país de la Revolución Energética, a través de la aplicación de un Plan destinado a la venta y sustitución de efectos electrodomésticos en los núcleos familiares. Este proceso de distribución, conciliación, control y cobro de los efectos electrodomésticos y otros artículos, del que se han beneficiado casi todas las familias cubanas, puede considerarse como uno de los logros del país en materia económica. Se inicia con la entrega o el cambio de los efectos electrodomésticos en las viviendas por los Trabajadores Sociales a los miembros del núcleo familiar, previa firma del compromiso de pago. ${ }^{4} \mathrm{~A}$ partir de ese instante se debe efectuar la relación de compraventa mediante el pago en efectivo,

\footnotetext{
Compromiso de Pago: Documento emitido en original y dos copias por el Trabajador Social en el momento que entrega el efecto electrodoméstico, por el nuevo método de distribución a la población vinculado con el plan de desarrollo energético, firmado por ambas partes, mediante el cual el beneficiario se compromete a pagar en el término de 30 días naturales. Tomado de las Normas de Programas Especiales, Manual de Instrucción la Oficina Nacional de Administración Tributaria (ONAT), 1ª Edición, de 9 de febrero de 2007, pág. 3.
} 
tomando como base un convenio legal o la entrega del cheque bancario en el establecimiento minorista, acciones previstas para ser ejecutadas en el período de treinta días naturales.

Para obtener el cheque referido, el miembro del núcleo familiar que asume el compromiso de pago debe entregar al Banco el modelo previamente solicitado de Solicitud de Contrato de Créditos Sociales. Este modelo de solicitud de contrato se caracteriza por consignar una relación de datos particulares del solicitante, de suma importancia para determinar la procedencia o no de la emisión del crédito bancario, datos que son acreditados por la Entidad donde labora de conjunto con el Banco; o exclusivamente por el Banco en los casos de jubilados. Una vez emitido el crédito, el sujeto lo entrega en la Unidad Comercial correspondiente, también denominada bodega de la red minorista del MINCIN a que pertenece. La Unidad Comercial deposita el cheque o el efectivo en la Zona Comercial correspondiente (Unidad Básica de Comercio). Cuando el cheque o el efectivo se encuentra bajo la custodia de la Unidad Depositante, se debe depositar en una cuenta de la Dirección Municipal de Finanza creada en el Banco de Crédito y Comercio (BANDEC), por ser esta última entidad la encargada de llevar el control de los equipos distribuidos en las diferentes zonas.

El Plan vinculado a la Revolución Energética, a pesar de haber sido elaborado con la finalidad de lograr el ahorro de energía eléctrica para el bienestar de toda la población cubana y de la nación en su conjunto, se ha limitado en su normativa a regular la entrega del artículo y prever que el beneficiado pague lo debido, sin que conste en un documento oficial la titularidad del bien adquirido a favor del propietario del bien cambiado en los casos de sustitución de artículos; o a favor del miembro del núcleo familiar comprometido con el pago en los casos de venta del artículo si media conformidad entre todos los miembros; o a favor de todos los miembros en caso de conflicto. Esta deficiencia genera los siguientes inconvenientes:

- Que el Derecho en determinados conflictos se vea imposibilitado de brindar seguridad jurídica al que se presume titular legítimo del bien objeto de litis.

- La aplicación deficiente de la teoría del título y el modo ${ }^{5}$ como sistema general de adquisición derivativa de los derechos sobre bienes en nuestro país, debido al desarrollo de relaciones de compraventa en las que el Estado no garantiza la transmisión legal (Título

La adquisición del derecho de propiedad puede ser originaria o derivativa. Es derivativa cuando se adquiere el derecho de propiedad con base en un precedente derecho de propiedad en poder de un titular distinto del sujeto que pretende adquirirlo. De ahí que se genere una relación jurídica sobre bienes entre transmitente y adquirente, jugando un papel importante el Titulo (titulus), entendido como la convención entre los sujetos de la relación jurídica que da la posibilidad de la transmisión del derecho de propiedad, y el Modo (traditio) como hecho que consuma, materializa y completa la adquisición de la propiedad. 
de Propiedad) del efecto electrodoméstico al comprador, ni en los casos en los que éste ha liquidado la deuda y el crédito bancario.

- La afectación de la propiedad personal de los ciudadanos cubanos sobre aquellos bienes muebles sometidos al Plan, de la siguiente manera:

a) Cuando se produce la sustitución de efectos electrodomésticos, el propietario del bien cambiado tiene una doble afectación de su patrimonio: pierde el dominio pleno sobre el bien que cede y paga el valor del bien adquirido con los ingresos personales que integran su propiedad personal, frutos del trabajo propio, sin poder incorporarlo legalmente a su patrimonio, con lo que queda sometido al uso, disfrute y posesión de todos los miembros del núcleo familiar en igualdad de condiciones, sin un titular legítimo que ostente la propiedad exclusiva del mismo.

b) Cuando se produce la entrega de efectos electrodomésticos, el miembro del núcleo familiar que asume el compromiso de pago debe efectuar el pago que pesa sobre los bienes que conforman su propiedad personal, sin ingresar legalmente a su patrimonio el bien pagado, sometido aun, según la política pública, a la posesión, uso y disfrute de todos los miembros del núcleo familiar en igualdad de condiciones, sin definirse un derecho de propiedad exclusivo sobre el bien a favor del miembro que cubre la deuda o un derecho de copropiedad a favor de todos.

La entrega del efecto electrodoméstico sin título de propiedad podría fundamentarse o justificarse en uno de los ideales trazados por el Plan, consistente en la entrega de artículos para uso y disfrute de los núcleos familiares en su conjunto y no exclusivamente para uno de sus miembros, pero lo cierto es que no se previeron los conflictos que podían suscitarse en los núcleos familiares en torno a los derechos reales que demandan estos artículos. Tampoco se tuvo en cuenta que en la sustitución de artículos estaban inmersos bienes de propiedad personal de uno de los miembros del núcleo familiar y no de todos, lo que equivaldría a garantizar el bienestar de todos los miembros sin lesionar el derecho exclusivo del que ostenta la propiedad personal.

La aplicación del Plan vinculado a la Revolución Energética, si bien es cierto que tributa al desarrollo económico del país, como se ha venido explicando, porque contribuye al ahorro energético y beneficia a la inmensa mayoría de las familias cubanas con equipos de alto desarrollo tecnológico, garantes de las comodidades domésticas principales; se ha efectuado sin un proceso previo de análisis y adopción de medidas ajustadas al Derecho. Por tal motivo, este avance económico va acompañado de incertidumbres que giran, por un lado, en torno al tratamiento a que estarán sometidos estos bienes en materia sucesoria o al momento de liquidar la comunidad matrimonial de bienes y, por otro lado, a circunstancias en las cuales 
el propietario del bien cambiado se ha visto amenazado generalmente por la persona que asumió el compromiso de pago y que pretende acreditarse la titularidad del bien, por aquella que ostenta la posesión del mismo, o por otro miembro del núcleo familiar que pretende privarlo del uso y disfrute del bien, sin que el Derecho pueda otorgarle respaldo jurídico, lo que reafirma que en la actualidad "la seguridad jurídica se ha visto amenazada esencialmente en el terreno de los hechos, donde la certeza del Derecho es más un mito que una realidad". 6

Estas y otras situaciones han generado lagunas sólo salvables de manera deficiente por el Derecho, a través del ejercicio de acciones como las de reconocimiento de propiedad del bien por el presunto titular en los procesos de reconocimiento de dominio y la acción de amparo en la posesión para los casos de personas víctimas de actos de perturbación o despojo del bien poseído, acciones que no requieren del título de propiedad para instar al Tribunal, mientras sigue inoperante el Derecho ante la existencia de litigios que demanden el ejercicio de una acción reivindicatoria que no puede efectuarse por la falta de un documento acreditativo del derecho de propiedad. Sucesos que han hecho inevitable la connotación social y jurídica, con predominio del descontento y desesperación de la población.

La falta de soluciones rápidas y efectivas, que eviten complejizar la labor de los juristas en la aplicación de las normas jurídicas y permitan que los ciudadanos recuperen sus bienes o eviten su pérdida, puede condicionar una práctica judicial encaminada a solventar la panorámica actual con la admisión de demandas contentivas de la acción reivindicatoria, a pesar de no poder demostrarse la titularidad del derecho de propiedad del demandante, lacerando así el Derecho. Esta supuesta solución emergente de dar curso a un proceso ordinario o sumario con ejercicio de una acción reivindicatoria sustentado en un compromiso de pago, que por sí solo no es representativo de la existencia un derecho real sino más bien de un derecho de crédito, no es la solución que debe recetarse ante la situación imperante, pues se violentaría uno de los presupuestos indispensables para el ejercicio de la acción reivindicatoria ${ }^{7}$. Tampoco es procedente establecer una acción reivindicatoria ante el Tribunal para solucionar un conflicto

6 Pérez Luño, Antonio Enrique, La seguridad jurídica. Catedrático de Filosofía del Derecho de la Universidad de Sevilla, disponible en: www.iustel.com consultado en fecha 7 de febrero de 2011.

7 Para ejercer la acción reivindicatoria se exigen 3 requisitos: 1- acreditar la propiedad del bien objeto de litis por la parte demandante. 2- identificar el bien objeto de debate. 3- demandar al que ostenta el bien sin causa legítima. En el caso que se explica en el trabajo, no se puede demostrar la propiedad de un bien con un compromiso de pago. “... la propiedad y la posesión van ordinariamente unidas, y cuando ello no acontece, mediante la acción reivindicatoria se permite al propietario que recobre la posesión indebidamente perdida, resultando por ello indispensable para la viabilidad de una acción de esta naturaleza, la concurrencia inexcusable de tres requisitos, y cuya prueba corresponde al actor, en aplicación del principio general, de la carga de la prueba, a saber, el título legítimo de dominio, identificación de la cosa que se pretende reivindicar con la que está en poder del demandado, y la detentación injusta de quien la posee (...)”. Tribunal Supremo, Sala de lo Civil y de lo Administrativo, Sentencia No 352 de 30 de abril del 2004. Único Considerando. Sentencia $\square 8$ de 26 de enero del 2005. Segundo Considerando. Sentencias No 98 y No 99 de 24 de febrero del 2006. Único considerando de ambas sentencias, todas del ponente Acosta Ricart. 
de esta modalidad y luego establecer un proceso de reconocimiento de propiedad.

Nos encontramos ante una disyuntiva jurídica que debe calzarse con la implementación de medidas, mecanismos o medios efectivos y rápidos que enmienden lo ocasionado hasta el momento y eviten los sucesos futuros. Como medida emergente pudiera dictaminarse la creación de una norma legal o de un documento contentivo de medidas administrativas que dispongan lo siguiente:

- Para los supuestos en los que se ha efectuado la entrega o cambio del bien mueble deberá realizarse un censo donde se destine al personal calificado a la emisión de títulos de propiedad de la siguiente manera:

1- En casos de pagos de efectos electrodomésticos mediante cheque:

a) a favor de las personas que previa entrega del título de propiedad demuestren haber sido propietarios del efecto electrodoméstico sustituido aunque sean otras personas las que se encuentren sujetas al crédito social. En su defecto, para aquellos casos donde no pueda demostrarse la plena titularidad sobre el bien cambiado, se emitirá título de propiedad a favor de la persona sujeta al crédito social.

b) a favor del miembro del núcleo familiar comprometido con el compromiso de pago en casos de entrega de efectos electrodomésticos, previa constancia en una planilla del consentimiento del resto de los miembros del núcleo familiar; o en caso de conflictos a favor de todos los miembros del núcleo familiar (esta planilla debe estar foliada, acuñada y consignar los datos del emisario, de los efectos electrodomésticos entregados y la firma de todos los miembros del núcleo familiar a continuación de sus nombres, apellidos y carné de identidad).

2- En casos de pago de efectos electrodomésticos en efectivo: Se considerarán usufructuarios onerosos adquirentes de la propiedad del bien hasta tanto no realicen el pago íntegro del mismo. No han de declarase temporalmente poseedores del bien porque pueden convertirse en propietarios del mismo por usucapión antes de culminar el pago del artículo.

- Para los supuestos en los que todavía no se ha efectuado el cambio o entrega de equipos electrodomésticos y otros artículos, deberá realizarse el acto de entrega (traditio) del bien junto al título legítimo de dominio.

Estas u otras acciones podrían solucionar la demanda cada vez más creciente de situaciones jurídicas con tales características. Con Independencia de las medidas que se adopten, lo que si resulta de urgencia es la necesidad de brindar una solución racional y jurídica que dé satisfacción a las pretensiones sociales, pues el Derecho no cuenta hasta el momento con los 
mecanismos suficientes que garanticen protección jurídica a las relaciones jurídicas suscitadas, siendo necesario que se adapte a la realidad imperante.

\section{Conclusiones}

- En el socialismo, la propiedad estatal socialista condiciona la existencia de la propiedad personal al garantizar los medios fundamentales para la satisfacción de las necesidades materiales y espirituales de los ciudadanos.

- La propiedad personal, como forma de apropiación de bienes por los ciudadanos, no es suficiente para satisfacer las necesidades e intereses personales de su titular, es preciso la formulación de normas que reconozcan el derecho y las facultades que ostenta el titular sobre el bien y garanticen mecanismos de protección jurídica ante la vulneración de su derecho.

- El desarrollo en el país de ciertas políticas públicas destinadas a generar beneficios económicos y sociales, puede llegar a lacerar el Derecho si no son adoptadas en sintonía con el ordenamiento jurídico.

- La falta de titularidad sobre los efectos electrodomésticos cambiados o entregados, además de afectar la propiedad personal sobre bienes muebles, ha condicionado la aplicación deficiente de la teoría del título y el sistema general de adquisición derivativa de los derechos reales en nuestro país, con el desarrollo de relaciones de compraventa que no garantizan la transmisión legal del efecto electrodoméstico al comprador; así como la imposibilidad de someter estos bienes a un tratamiento en materia sucesoria o de liquidación de la comunidad matrimonial de bienes.

- La panorámica cubana actual, con la aplicación del Plan vinculado a la Revolución Energética y su incidencia en la propiedad personal de los ciudadanos cubanos, puede condicionar el ejercicio jurídico y conllevar a una práctica judicial que asuma la postura de equiparar, en determinados procesos, el compromiso de pago entregado con el efecto electrométrico al documento acreditativo de la titularidad de un derecho real sobre el bien mueble objeto de debate, no siendo esta tendencia la solución que debe recetarse. Se precisa la adopción emergente de medidas jurídicas y administrativas que garanticen la emisión de títulos de propiedad y eliminen los conflictos suscitados hasta el momento.

- Proponemos, para solucionar los inconvenientes surgidos con la aplicación del Plan, la creación de una norma legal o de un documento contentivo de medidas administrativas que dispongan para los supuestos en los que se ha efectuado el cambio o entrega del efecto electrodoméstico, la realización de un censo que posibilite la emisión de títulos de propiedad a favor de las personas correspondientes; y para los supuestos futuros de cambio o entrega de artículos, su entrega acompañado del título legítimo de dominio. 


\section{Referencias Bibliográficas}

- Lacruz Berdejo, José Luis et al, Elementos de Derecho Civil, Derechos Reales, volumen primero, tercera edición, DYKINSON, Madrid, 2008.

- Fernández Bulté, Julio; C arReras Cuevas, Delio; Yánez, Rosa María, Manual de Derecho Romano, La Habana, Editorial Pueblo y Educación, 1982.

- Pérez Hernández, Lissette, José Antonio Hernández Ruiz, Apuntes sobre la Propiedad, desde un punto de vista constitucional, disponible en: http://www.fd.cug.co.cu. consultado el 20 de julio de 2011.

- Pérez Luño, Antonio Enrique, La seguridad jurídica. Catedrático de Filosofía del Derecho de la Universidad de Sevilla, disponible en: www.iustel.com consultado en fecha 7 de febrero de 2011.

- Rapa Álvarez, Vicente, "Propiedad Personal y otras formas de propiedad no previstas en la Constitución”, en Revista Jurídica, La Habana, núm. 3, 2009.

- Rivero Valdés, Orlando, Temas de Derechos Reales, Editorial Félix Varela, La Habana, 2001

- Rodríguez Saif, María Julia, La propiedad personal de la vivienda. Función social. Prerrogativas $y$ limitaciones, disponible en: http://www.fd.uo.edu.cu. consultado el 13 de julio de 2011.

\section{Legislación consultada:}

- Constitución de la República de Cuba de 24 de febrero de 1976, reformada en 1992 y 2002, Gaceta Oficial Extraordinaria No. 3 de 31 de enero de 2003.

- Ley No. 59 de 16 de julio de 1987, “Código Civil Cubano”, Editorial de Ciencias Sociales, La Habana, 1989.

- Resolución No. 96 de 2 de junio de 2010, "Normas y Procedimiento para la Venta y Sustitución de los equipos de Refrigeración y Aire Acondicionado", del Programa de Ahorro Energético en el Sistema del Ministerio del Comercio Interior.

\section{Otras disposiciones:}

- Normas de Programas Especiales, Manual de Instrucción la Oficina Nacional de Administración Tributaria (ONAT), 1ª Edición, de 9 de febrero de 2007.

- Medida para el pago convenido a personas no sujetas al crédito social de 17 de abril de 2009. 


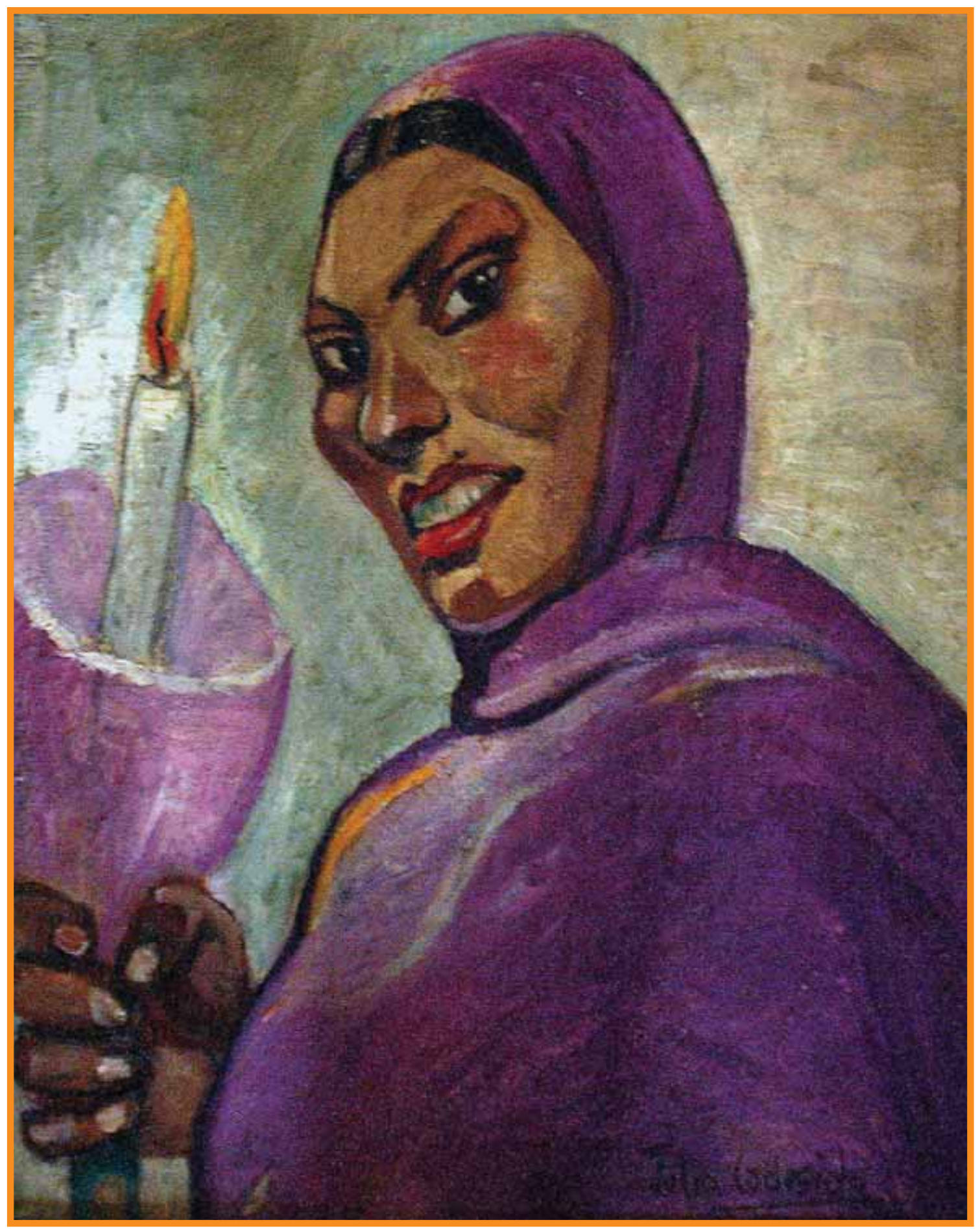

Morena. Colección Néstor Benavides. 